\title{
O ENSINO MÉDIO NO PLANO NACIONAL DE EDUCAÇÃO 2011-2020: SUPERANDO A DÉCADA PERDIDA?
}

\author{
AcaCia Zeneida Kuenzer ${ }^{*}$
}

\begin{abstract}
RESUMO: Este artigo tem como objeto as propostas para o ensino médio que deverão ser contempladas no Plano Nacional de Educação (PNE), a partir da Conferência Nacional de Educação, de 2010. Apoiado nos documentos produzidos pelo MEC, pelo CNE e pela sociedade civil, o texto analisa os dados referentes ao acesso e à qualidade do ensino médio no âmbito do PNE 20012010. A partir desta análise, o texto aponta para a necessidade de conferir materialidade ao discurso acerca da universalização da educação básica com qualidade social, para o que é fundamental a institucionalização do Sistema Nacional de Educação como elemento articulador de um esforço coletivo, tendo em vista a ampliação do acesso e da qualidade do ensino médio. $\mathrm{O}$ texto analisa a estagnação ocorrida no período de 2001-2010 e aponta a inversão da dualidade estrutural, mediante a desqualificação da oferta de ensino médio de educação geral para os que vivem do trabalho. Ao longo da análise, a autora enfatiza as metas que deverão ser consideradas na elaboração do novo PNE, tendo em vista a qualidade e a universalização do ensino médio.

Palavras chave: Ensino médio. Plano Nacional de Educação. Educação básica.
\end{abstract}

\section{High SCHOOL EDUCATION IN THE NATIONAL PLAN FOR EDUCATION FOR 2011-2020: MAKING UP FOR THE LOST DECADE?}

ABSTRACT: This paper explores the proposals for high school education that will be included in the National Plan for Education, which was launched at the 2010 National Conference on Education.

Doutora em Educação e professora titular aposentada da Universidade Federal do Paraná (UFPR).E-mail:www.acaciazk@uol.com.br 
Based on documents produced by the Ministry of Education, the National Education Council and the civil society, it analyzes the data concerning the access to and the quality of high school education as provided in the 2001-2010 National Plan for Education. It then points out the need to materialize the discourse on the universalization of basic education with social quality. To do so, the $\mathrm{Na}$ tional Education System must be institutionalized as an articulating element of a collective effort aiming to provide high school education with a wider access and a higher quality. Next, the text analyzes the stagnation of the first decade of the $21^{\text {st }}$ century. It points out that there was an inversion of the structural duality through the disqualification of the general high school education provided to those who work for a living. Throughout the analysis, the author emphasizes the goals that should be considered within the context of the new National Plan for Education, to attain a universalized, quality high school education.

Key words: High school education. National Plan for Education. Basic education.

\section{Introdução}

A

o redigir esse artigo, cuja finalidade é contribuir com o debate sobre o ensino médio a ser realizado no processo de elaboração e acompanhamento do Plano Nacional de Educação (PNE) 20112020, uma questão de fundo, já apontada pelo Conselho Nacional de Educação (CNE) no documento elaborado para subsidiar o novo PNE, precisa ser explicitada: as limitações da análise, decorrentes da ausência de uma avaliação consistente do PNE 2001-2010, ${ }^{1}$ uma vez que este elidiu, em sua formulação, indicadores que permitissem acompanhar o desenvolvimento no tocante às metas estabelecidas para o decênio. Ao mesmo tempo, a não explicitação dos mecanismos de financiamento acabam por fazer do atual PNE antes um rol de boas intençôes do que um efetivo documento de planejamento a orientar objetivamente as ações, a permitir o acompanhamento dos investimentos e a avaliação dos resultados, em um processo de análise crítica que deveria ter se desenvolvido no transcurso do decênio.

Assim, ficam limitadas a análise e a elaboração de proposições, quando as metas não são passíveis de avaliação pela ausência de indicadores e quando os parâmetros relativos ao financiamento não são claramente 
explicitados. Estes limites, contudo, seriam minimizados se o governo tivesse promovido uma criteriosa análise da situação real da educação brasileira, discutindo-a com a sociedade civil, não apenas apresentando dados brutos, mas séries históricas, matrículas por idade, distorção idade-série, relação entre escolaridade, formação profissional e emprego, entre outros, de modo a mostrar como de fato evoluíram o acesso e a permanência nos diferentes níveis, etapas e modalidades de ensino e suas relações com a ocupação e com o acesso à cultura. A ausência de explicitação destes dados e do debate com a sociedade civil, por si só, já revela os limites deste processo, que acaba se transformando em formalidade. Cumpre destacar, ainda, que os dados disponíveis são descontinuados, dificultando sobremaneira a análise dos indicadores que permitiriam um diagnóstico de qualidade, a partir do qual pudessem ser estabelecidas metas realistas para o próximo decênio.

Evidentemente, a explicitação destes limites não pode ser entendida como negação das positividades que o processo democrático de construção de um PNE pode trazer, em termos de negociação entre sociedade civil e governo acerca das metas que devem orientar as açóes do Estado e seu acompanhamento e controle, no que tange aos direitos fundamentais. Ao contrário, esses limites devem orientar o debate acerca das formas de seu enfrentamento; daí a razão de explicitá-los. Contudo, é necessário indicar que é sob estes limites que o presente artigo se constrói.

Explicitados os limites de método, há que anotar os decorrentes do conteúdo: com relação ao ensino médio, com suas históricas mazelas, o que há de novo a pontuar para o novo Plano, senão o enfrentamento das dificuldades que vêm sendo apontadas tanto pela sociedade civil quanto pelo governo, desde a década de 1980?

Mais uma vez, portanto, há que retomar as clássicas teses, pinceladas com alguns novos matizes que tornam a análise desta etapa da educação básica mais preocupante, com o intuito de fortalecer as posições políticas comprometidas com a construção objetiva, e não apenas formal, dos direitos daqueles que vivem do trabalho. Esta última afirmação circunscreve a direção a ser dada ao texto: o ensino médio público, uma vez que o ofertado aos filhos da burguesia e da pequena burguesia pela iniciativa privada atende aos interesses de seu públicoalvo, não se constituindo em motivo de preocupação. 
Assim, o eixo a conduzir a análise será, mais uma vez, a universalização de um ensino médio com qualidade social, tal como preconiza a legislação educacional vigente. Para tanto, serão tratadas as seguintes dimensões: o ensino médio como parte integrante da educação básica, o que remete à constituição do Sistema Nacional de Educação; a universalização do acesso; a garantia da permanência e do sucesso mediante políticas de assistência ao estudante; a construção da qualidade social, para o que concorrem a concepção pedagógica, a organização curricular, os padróes mínimos e a formação de professores.

O ensino médio como etapa da educação básica: o PNE como mediação no âmbito do Sistema Nacional de Educação

A primeira dimensão a apresentar, tendo em vista a elaboração do PNE 2011-2020, é o compromisso com a construção das condições objetivas, para além do discurso, do ensino médio como etapa efetivamente integrante da educação básica, o que remete não só à universalização, mas ao tratamento integrado do trajeto curricular a ser percorrido da educação infantil ao ensino médio, a partir da nova redação dada ao inciso I do artigo 208 da Constituição em vigor, pela Emenda Constitucional n. 59/2009, que assegura que a educação básica é obrigatória e gratuita dos 4 aos 17 anos de idade, devendo ser ofertada inclusive para todos os que a ela não tiveram acesso na idade própria.

Embora já presente na LDB de 1996, esta concepção fica reforça$\mathrm{da}$, à medida que passa a ser tratada como categoria central nas novas Diretrizes Curriculares Nacionais Gerais para a Educação Básica, constantes do Parecer CNE/CEB 07/2010.

No âmbito das concepçôes e políticas educacionais, há que considerar que a concepção de educação básica trazida pela nova LDB representa uma significativa mudança em relação às legislações anteriores, no sentido da democratização da oferta de educação pública de qualidade para toda a população, mas em particular para aqueles que só têm na escola pública o espaço de acesso ao conhecimento e à aprendizagem do trabalho intelectual.

Superando a fragmentação das legislações anteriores, que atribuíam ao Estado reduzido compromisso com a oferta pública, a LDB de 1996 propõe a educação básica como concepção que assegura a integração entre 
as diferentes etapas e modalidades de ensino, de modo a propiciar a todo e qualquer cidadão, respeitando a diversidade, a formação considerada como o mínimo necessário à participação na vida social e produtiva. Suas finalidades estão definidas no artigo 22: "A educação básica tem por finalidades desenvolver o educando, assegurar-lhe a formação comum indispensável para o exercício da cidadania e fornecer-lhe meios para progredir no trabalho e em estudos posteriores".

É a concepção de educação básica que assegura a organicidade da educação nacional, através do princípio da integração:

- das etapas: a educação infantil, o ensino fundamental e o ensino médio;

- das modalidades: educação profissional, educação do campo, educação especial, educação de jovens e adultos, educação indígena.

Por compreender a educação como totalidade, já no primeiro capítulo a LDB a define em seu conceito mais amplo, admitindo que ela supera os limites da educação escolar por ocorrer no interior das relaçôes sociais e produtivas; reconhece, pois, as dimensões pedagógicas do conjunto dos processos que se desenvolvem em todos os aspectos da vida social e produtiva. Esta concepção incorpora a categoria trabalho, reconhecendo a sua dimensão educativa, ao mesmo tempo em que reconhece a necessidade da educação escolar vincular-se ao mundo do trabalho e à prática social.

A incorporação de todas as modalidades de educação na concepção de educação básica, estabelecendo sua integração e assegurando sua organicidade, decorre desta concepção de educação como totalidade. Isso significa organizar a educação básica como um sistema que não admite formas paralelas que comprometam a assumida integração entre as etapas e modalidades de ensino oferecidas pela educação escolar e as demais ações educativas que ocorrem no conjunto das práticas sociais. Pretende assegurar, dessa forma, tanto a organicidade interna à educação básica, quanto a externa, articulando, pela mediação da educação, conhecimento, trabalho e cultura.

Por conceber a educação básica como condição de exercício de cidadania e, portanto, como direito, prevê a extensão de sua gratuidade, posto que é dever do Estado para com seus cidadãos. Com relação a 
este ponto, há que registrar, no que diz respeito ao ensino médio, os avanços relativos à democratização do acesso trazidos pela Lei n. $12.061 / 2009$, quando altera o inciso II do artigo 4 e o inciso VI do artigo 10 da LDB: a ampliação do compromisso do Estado, que era indicado como apenas a extensão progressiva, para o atendimento de todos os interessados, sejam jovens ou adultos, na modalidade regular ou de educação de jovens e adultos (EJA), garantindo aos trabalhadores condições de acesso e permanência. Dessa forma, a democratização do acesso ganhou força constitucional, pelo menos para os ensinos fundamental e médio.

Para assegurar a objetivação desta concepção, a União chama a si a coordenação da política nacional de Educação, com a finalidade de assegurar a articulação dos diferentes sistemas de ensino, seus níveis, etapas modalidades, uma vez que os recursos são finitos, havendo que definir prioridades e responsabilidades. Neste contexto, o PNE, quando resulta do amplo debate entre governo e sociedade civil, expressa os acordos possíveis que mediam o enfrentamento das contradições que constituem o modo de produção capitalista.

O SNE, cuja sistematização é o eixo do PNE 2011-2020, constitui-se no mecanismo articulador do novo pacto federativo que conduzirá ao atendimento das metas propostas para o decênio. Respeitando a autonomia das unidades federadas, cabe ao SNE gerenciar o regime de colaboração, mediante ações integradas dos poderes públicos das diferentes esferas federativas, para que, a partir de diretrizes e objetivos comuns, sejam atingidas as metas que assegurem o desenvolvimento do ensino em seus diferentes níveis, etapas e modalidades, buscando diminuir, tanto quanto possível, a desigualdade relativa à democratização do acesso com qualidade, consideradas as diversidades e as diferenças regionais.

A organização estratégica, portanto, do ponto de vista da gestão, está claramente definida: consideradas as políticas nacionais de Educação, o PNE articula as instâncias no processo democrático de definição de prioridades e metas e expressa os consensos possíveis, ao passo que o SNE responsabiliza-se pelo seu desenvolvimento, sempre com o controle da sociedade civil, que deve organizar-se para tal. Resta colocar esta diretriz estratégica em prática e assegurar sua efetivação, para o que os controles públicos e da sociedade civil são essenciais. 
A análise desenvolvida até aqui já delineia alguns pontos importantes que deverão pautar o debate no âmbito do PNE 2011-2020 no que diz respeito ao ensino médio: definir metas e indicadores claros para esta etapa, as responsabilidades pela sua execução e as formas de acompanhamento e controle que deverão ser realizadas no período de implementação do Plano, prevendo fóruns específicos periódicos, pelo menos a cada três anos, para revisão de rumos a partir de dados que explicitem claramente os percentuais atingidos em relação ao proposto para o decênio. Não obstante o PNE proponha a realização de um fórum ao quinto ano, no caso específico do ensino médio, dada a magnitude das açôes que se fazem necessárias, há que considerar a realização de acompanhamento em períodos mais curtos, a fim de que as correções de rumo possam ser realizadas.

Estas providências são fundamentais para que o novo PNE não repita o ocorrido no decênio que se encerra, uma vez que a não definição de metas, indicadores, mecanismos de financiamento e responsabilidades, a par da ausência de dados que apresentem a realidade de forma transparente, inviabiliza não só a avaliação consequente do Plano, como também um adequado estabelecimento de metas realistas para o próximo decênio.

Enfatize-se que, em se tratando de ensino médio como etapa da educação básica na perspectiva do direito à educação, o que significa promover a sua democratização, as providências anteriormente elencadas, que implicam a institucionalização do SNE, são mais dramáticas, dado o reduzido percentual de jovens e adultos atendidos e o número decrescente, ano a ano, de matrículas nesta etapa, o que será objeto de análise no item a seguir. Isso significa que a promoção de efetivo avanço na democratização do acesso e na ampliação da permanência vai exigir um novo pacto federativo, cimentado por um forte investimento, principalmente pelas esferas federal e estadual, mesmo que se considere apenas a dimensão quantitativa.

Ou seja, passa a ser fundamental a realização de um rigoroso diagnóstico que permita identificar as necessidades educativas, contemplando as especificidades locais e regionais, a diversidade sociocultural, o corpo de docentes e especialistas em educação, a estrutura física e material, a disponibilidade de bibliotecas e laboratórios, as peculiaridades da organização social do trabalho, as diferentes faixas etárias a serem 
atendidas, entre outros dados. O resultado desse diagnóstico será o ponto de partida para o estabelecimento de prioridades e metas a serem compartilhadas entre as diferentes esferas de governo, de modo a deflagrar um esforço concentrado, tendo em vista a expansão do acesso e da permanência no ensino médio, atualmente de responsabilidade majoritária da esfera estadual.

Com relação à concepção de ensino básico, há uma nova dimensão a considerar, já apontada no início deste texto: o planejamento pedagógico, que deverá contemplar, diferentemente do realizado até o presente, as etapas compreendidas, não como fragmentos que se sobrepõem, mas em sua dimensão de totalidade, o que supõe diretrizes curriculares comuns e uma base nacional mínima.

No plano nacional, as Diretrizes Curriculares Nacionais Gerais para a Educação Básica, pautadas pelos princípios de organicidade, sequencialidade e articulação, constantes do Parecer CNE/CEB n. 07/ 2010, já homologadas pelo ministro da Educação e publicadas no Diário Oficial da União (9 jul. 2010, seção 1, p. 10), já cumprem esta função, cabendo às unidades federadas, com base neste Parecer, elaborar as suas próprias diretrizes, uma vez que é de sua competência organizar, manter e desenvolver os seus sistemas de ensino, definindo com os municípios as formas de colaboração que possibilitem a progressiva extensão da oferta pública e gratuita.

Algumas unidades federadas, antecipando-se às diretrizes nacionais, já iniciaram este esforço, citando-se como exemplo o Paraná e o Mato Grosso. Neste último, sob a gestão da Secretaria de Educação e com a participação de docentes da educação básica e superior, apoiados por especialistas nas áreas de conhecimento e em pedagogia do trabalho, foi elaborada uma proposta de organização curricular que contempla o sequenciamento das etapas transversalizadas pelas áreas de conhecimento, que explicitam conhecimentos e capacidades desde o primeiro ciclo do ensino fundamental ao ensino médio, tratados mediante a articulação das disciplinas por área e das áreas entre si em eixos temáticos. $\mathrm{O}$ resultado deste trabalho coletivo foi submetido à ampla discussão, desde o primeiro semestre de 2010, em seminários por escola, por município, por região e, finalmente, no estado, sendo o Documento Final o resultado deste processo democrático, que contou com a participação do Sindicato dos Professores. 
A ampliação do acesso com garantia de permanência e de sucesso

Analisada a diretriz estratégica, como metodologia, é preciso discuti-la do ponto de vista do conteúdo, tratando especificamente do ensino médio. Para fazê-lo, serão elencados alguns dados que permitam configurar a dimensão do esforço a ser desenvolvido para a ampliação do acesso com garantia de permanência e de sucesso, embora com os limites impostos pela forma como os dados estão disponíveis, já apontados na Introdução.

O ponto de partida para esta análise é a política que orienta a estruturação do novo PNE no que diz respeito ao ensino médio: a sua universalização com qualidade social, por meio de açôes que visem à inclusão de todos no processo educativo, com garantia de acesso, permanência e conclusão de estudos com bom desempenho; respeito e atendimento à diversidade socioeconômica cultural, de gênero, étnica, racial e de acessibilidade, promovendo igualdade de direitos; e o desenvolvimento da gestão democrática (CONAE 2010, p. 63).

Os dados disponíveis para o ensino médio, embora descontinuados e com os limites já apontados, apresentam um quadro preocupante, uma vez que apontam crescente retração quando comparados à evolução das matrículas ocorrida entre 1991 e 2001 e ao movimento ocorrido no ensino fundamental entre 2000 e 2008.

Assim é que, se as matrículas no ensino médio cresceram 32,1\% entre 1996 e 2001, passando de aproximadamente 5,7 milhōes para 8,4 milhōes, no quinquênio seguinte cresceram apenas $5,6 \%$, passando a decrescer a partir de 2007 , de modo a configurar crescimento negativo de $-8,4 \%$ de 2000 a 2008 , segundo os dados do Instituto Nacional de Estudos e Pesquisas Educacionais Anísio Teixeira (INEP). ${ }^{2}$ Esta retração se acentua entre 2008 e 2009 , atingindo um percentual de $-3,2 \%$, sendo que, em 2008, foram 8.369.389 matrículas contra 8.337.160 em 2009; ou seja, em apenas um ano, uma diferença de 32.229 matrículas.

Os dados relativos à matricula, contudo, precisam ser desagregados para permitir uma melhor análise, embora se disponha apenas de dados descontinuados. Das matriculas em 2008, apenas 252.661 se localizaram no campo, ou seja, aproximadamente $3 \%$. Dos matriculados, apenas $48 \%$ têm entre 15 e 17 anos; esta taxa era de 45,3 em 
2005. A distorção idade-série cresceu de 0,38 para 0,54 entre 2000 e $2007 .^{3}$

Em 2006, do total dos matriculados no ensino médio nesta faixa etária, 58,4\% eram brancos e 37,4\% eram negros.

Em 2007, 41,3\% das matrículas foram feitas no turno noturno; como aproximadamente a metade dos matriculados tem 18 anos e mais, elas provavelmente referem-se, em sua expressiva maioria, a alunos que trabalham ou procuram trabalho. ${ }^{4}$

Quanto ao vínculo administrativo, o esforço é majoritariamente público-estadual, responsável por aproximadamente $85,8 \%$ das matriculas em 2008, as quais, acrescidas às federais, representam aproximadamente $87 \%$; ressalte-se que estes percentuais têm se mantido relativamente estáveis nos últimos anos. ${ }^{5}$

Os dados referentes ao fluxo, que indicam o grau de eficácia desta etapa de ensino, mostram o crescimento da taxa de repetência de 18,65\% em 2000 para 22,6\% em 2005; de evasão, de 8,0\% em 2000, para $10,0 \%$ em 2005; do tempo médio de conclusão de $3,7 \%$ para $3,8 \%$ no mesmo período. ${ }^{6}$

Os dados elencados, mesmo descontinuados e sem a necessária sistematização para conferir transparência e permitir análise qualifica$\mathrm{da}$, permitem inferir que, quanto à expansão do acesso, permanência e sucesso, não houve mudanças significativas, mostrando que, para o ensino médio, o PNE 2000-2010 não aconteceu.

Quando são tomadas outras dimensōes, como, por exemplo, a infraestrutura, as conclusões não são muito diferentes: no período de 2001 a 2007, as escolas que tinham biblioteca, telefone e copiadora passaram de $46 \%$ para $47,4 \%$. Já com os computadores, houve elevação do indicador: de $78,4 \%$ das escolas que tinham este equipamento em 2000, passou-se para $94,1 \%$ em 2007, porém apenas $70 \%$ delas fizeram uso pedagógico em $2007 .{ }^{7}$ Registre-se, também, que não há informações sobre o número e a qualidade destes equipamentos, o que torna o dado pouco expressivo.

Um dado relevante, e que explica em grande parte a ineficácia do Plano, diz respeito ao custo do aluno do ensino médio. Enquanto na Organização para a Cooperação e Desenvolvimento Econômico (OCDE), em 2004, este custo equivalia a R\$ 13 mil, na Argentina e no Chile a R\$ 2 mil; no Brasil, em 2008, era de apenas R\$1.500. ${ }^{8}$ 
Reiteram-se, portanto, as indicações já feitas anteriormente neste texto: os problemas continuam os mesmos, a década foi pedida para o ensino médio, e as soluções possíveis passam pela construção da concepção da educação básica no âmbito do SNE, mediante um PNE que, definindo metas claras a partir de diagnósticos consistentes, fontes e mecanismos de financiamento compatíveis com a dimensão do problema, seja o instrumento de articulação de um novo pacto federativo, pautado em um esforço expressivo que permita reverter este histórico quadro de desrespeito aos direitos dos que vivem do trabalho. Isso porque os dados, embora não permitam relações consistentes, são suficientes para mostrar que a oferta é majoritariamente pública, urbana e para os brancos, que os indicadores de acesso, sucesso e permanência apresentam evolução negativa, os fluxos apresentam represamento e a distorção idade-série atinge a metade das matrículas. E, de quebra, pelo menos a metade das matrículas é noturna, atendendo a alunos trabalhadores.

Com relação à qualidade, os dados disponíveis são os do Exame Nacional do Ensino Médio (ENEM) e do Índice de Desenvolvimento da Educação Brasileira (IDEB) e, embora possam ser discutíveis, do ponto de vista da concepção de avaliação adotada pelos docentes e especialistas comprometidos com a qualidade da educação para os eu vivem do trabalho, reforçam os matizes da desqualificação da oferta e do descaso do setor público com o ensino médio, como já evidenciaram os dados anteriormente analisados.

Os dados do IDEB, disponibilizados pelo INEP, ${ }^{9}$ mostram que, em 2007, no ensino médio, as escolas privadas alcançaram média de 5,6, ao passo que as escolas públicas atingiram a média de 3,2; a média nacional neste ano foi 3,5, atingindo 3,6 em 2009, para uma meta de 3,5. Se for mantido o mesmo crescimento apresentado desde 2005 (0,1 a cada 2 anos), contrariamente à tendência apresentada pelo ensino fundamental, a meta de 6 pontos em 2020, considerado o parâmetro da OCDE, não será atingida. Em face da priorização da expansão e melhoria da qualidade do ensino fundamental pelo PNE 2000-2010, a estagnação do ensino médio, também no que diz respeito à qualidade, era previsível.

Já os dados do ENEM para o ano de 2009 mostram que os mil piores resultados foram obtidos por escolas públicas, sendo $97,8 \%$ estaduais (ENEM, 2009). 
Estes dados, embora apresentem limites em face da concepção dos modelos de avaliação utilizados, apontam a necessidade de discutir sobre que qualidade se pretende para o ensino médio, na perspectiva dos que vivem do trabalho.

\section{A qualidade social}

A discussão da qualidade social a ser buscada para o ensino médio remete à análise da concepção que se tem defendido para os que vivem do trabalho, tomando como referência a dualidade estrutural e seus impactos sobre esta etapa da educação básica.

Já se tratou, em outro texto, de elucidar que a superação da dualidade estrutural não é uma questão pedagógica, uma vez que é socialmente determinada pela contradição entre capital e trabalho. Ou seja, a divisão entre trabalho intelectual e trabalho prático, que por muito tempo justificou duas redes de ensino médio, uma de educação geral para a burguesia e outra profissional para os trabalhadores, tem sua origem na separação entre a propriedade dos meios de produção e a propriedade do trabalho. Assim, a divisão técnica do trabalho a justificar dois percursos formativos não foi criada pelo modo taylorista/ fordista, tampouco será superada pelos novos paradigmas de organização do trabalho, uma vez que decorre do processo de valorização do capital. É desse processo que resultam as necessidades de desenvolver processos educativos, nas relações sociais e nas escolas, que disciplinem os trabalhadores operacionais e intelectuais para submeterem-se às diferentes formas de trabalho.

A origem da fragmentação do trabalho, portanto, não é a divisão técnica, mas sim a necessidade de valorização do capital, a partir da propriedade privada dos meios de produção, o que vale dizer que, se a divisão entre teoria e prática expressa a divisão entre trabalho intelectual e manual como estratégia de subordinação, tendo em vista a valorização do capital, esta ruptura só será efetivamente superada em outro modo de produção.

Em consequência, a superação da dualidade não é uma questão a ser resolvida através da educação, mediante novas formas de articulação entre o geral e o específico, entre teoria e prática, entre disciplinaridade e transdisciplinaridade; ou mediante uma nova concepção de 
competência que impacte as políticas e programas de formação de professores. A dualidade só será superada com a superação da contradição entre a propriedade dos meios de produção e a propriedade da força de trabalho.

Embora, como em todo processo contraditório, haja espaço para processos emancipatórios, é preciso reafirmar que o estatuto da escola burguesa se constrói, historicamente, à luz das demandas de valorização do capital, para o que os processos de capacitação ou disciplinamento da força de trabalho são vitais.

Conclui-se, portanto, que as dificuldades que têm pautado os processos de construção de uma proposta de qualidade para o ensino médio integrado, na perspectiva dos que vivem do trabalho, não podem ser resolvidas por soluções pedagógicas, uma vez que a ruptura entre o geral e o profissional, entre o trabalho intelectual e a atividade prática, está na raiz da constituição do modo de produção capitalista.

Embora a dualidade estrutural seja instituída pela natureza do capitalismo, há, contudo, mudanças na forma de objetivação desta categoria, em face das mudanças ocorridas no mundo do trabalho a partir do novo regime de produção flexível, que impactam significativamente a concepção do ensino médio para os jovens trabalhadores.

A hipótese com a qual a autora vem trabalhando nos últimos anos, provocada pelas pesquisas de Zibas (1993 e 2002) e por suas próprias investigaçôes (Kuenzer, 2006 e 2007), é a da inversão da proposta dual que, até os primeiros anos da década de 1990, apresentava a escola média de educação geral para a burguesia e a escola profissional para os trabalhadores. E, dadas as condições de precarização que as escolas médias públicas que atendem os que vivem do trabalho têm apresentado, a autora trabalha com a hipótese de que a educação geral, antes reservada à elite, quando disponibilizada aos trabalhadores, banalizou-se e desqualificou-se.

Esse modelo começou a ser invertido desde a metade dos anos de 1990, na esteira das políticas do Banco Mundial para os países pobres, que propunha a oferta de educação geral para os jovens, que não deveriam se profissionalizar precocemente. Assim é que, no Brasil, o Decreto n. 2208/97 separou a educação profissional e tecnológica do ensino médio, interrompendo uma trajetória histórica construída desde os anos de 1940 pelas Escolas Técnicas Federais, que se caracterizavam por ofertar 
educação profissional pública de qualidade, permitindo, com isso, aos jovens o acesso ao emprego e ao ensino superior.

A pesquisa de Zibas realizada no Chile, que, antes do Brasil, já havia generalizado o ensino médio de educação geral a partir das orientaçôes do Banco Mundial, é elucidativa acerca do caráter falacioso daquela proposta. Mostra a autora que, nestes dois países, embora por caminhos diferentes, o ensino médio atingiu níveis semelhantes de precarização, sempre com prejuízo para os que vivem do trabalho:

(...) a ênfase em educação geral para as escolas públicas pode significar, como parece ter acontecido no Chile, apenas o barateamento e a desqualificação da educação da maioria. Do mesmo modo, uma profissionalização superficial ou estreita, como se deu no Brasil, principalmente na década de 70, transforma-se, também, em mera fachada para o esvaziamento dos cursos quanto a conteúdos significativos. (Zibas, 1993, p. 29)

Este barateamento, decorrente da adoção do modelo de ensino médio de educação geral, não se deve a uma suposta natureza desqualificadora desta modalidade, mas à forma como ela se objetiva. Uma educação técnico-científica de bom nível não é incompatível com a produção de alta tecnologia e com a inserção do jovem em uma sociedade em permanente transformação, afirma a autora, mas exige elevado investimento; o desenvolvimento de um currículo amplo e articulado de caráter geral; exige professores qualificados e bem pagos, espaço físico adequado, com biblioteca, laboratórios, computadores, quadras esportivas e outros recursos. Este custo elevado, assumido pela burguesia nas escolas privadas, é incompatível, contudo, com as possibilidades de financiamento do setor público. O resultado é um arremedo de educação, que, antes de ser geral e sólida, é apenas genérica e superficial, com prejuízos irreparáveis para a classe trabalhadora.

Com a mudança de governo em 2003, tendo Luiz Inácio Lula da Silva assumido a presidência da República, o movimento de oposição à ruptura entre educação geral e profissional, levado a efeito pelo Decreto n. 22008/97, ganhou força, até que, em 2004, o Decreto n. 5.154 restabeleceu a possibilidade da articulação mediante a modalidade "ensino médio integrado", que passou a compor o texto da LDB por força da Lei n. 11.741/2008.

A justificativa para esta proposição, reconhecida a centralidade da categoria trabalho nos processos de formação humana, nas dimensões 
ontológica, epistemológica e histórica, fundamenta-se na compreensão de que a formação geral e a educação profissional, desde que compreendidas como articulação entre ciência, cultura e trabalho, na perspectiva da politecnia, não se opõem, mas, contrariamente, se integram e, nesse sentido, asseguram melhor qualidade, principalmente para os que vivem do trabalho. Assim, desde que observadas as finalidades da educação básica, a integração entre educação geral e profissional pode ser tratada como uma modalidade do ensino médio, a atender as especificidades dos jovens que já trabalham.

A oferta da modalidade de educação profissional integrada ao ensino médio, contudo, ainda é restrita, embora tenha sido ampliada significativamente com a expansão dos Institutos Federais de Educação; do mesmo modo, os cursos técnicos ofertados mediante concomitância interna ou externa pelas redes estadual e federal, regulares ou na modalidade PROEJA, respondem por reduzido percentual de matrículas, em face do elevado custo e também de seu caráter seletivo.

De modo geral, para os jovens e adultos que vivem do trabalho, a modalidade mais acessível é o ensino médio de educação geral, em que as matrículas no turno noturno respondem a aproximadamente $50 \%$ do total, a distorção idade-série é elevada e os índices de evasão e repetência se ampliam, em escolas cujas condições de trabalho pedagógico são precarizadas, conforme se analisou anteriormente. Ou seja, quando a modalidade de educação geral passou a ser disponibilizada para os trabalhadores sob o discurso de sua democratização, isso foi feito de forma desqualificada.

A inversão da dualidade, portanto, é a nova realidade da escola média para os trabalhadores, que têm como alternativa a modalidade de educação geral. A educação tecnológica de qualidade ofertada pela rede pública, de modo geral, é frequentada por jovens de classe média, que vêem nela uma alternativa de inclusão no mundo do trabalho, de continuidade dos estudos em nível superior e de ascensão social.

Resta verificar se a afirmativa do Banco Mundial, relativa ao caráter democrático da educação geral, tal como se caracteriza na oferta para os que vivem do trabalho, se confirma. Para tanto, contribui o estudo realizado por Ribeiro e Neder (2009), que analisa a desocupação entre os jovens pobres e não pobres, tomando como referência desvantagens relativas à escolaridade. 
O estudo foi realizado com jovens a partir dos 18 anos, para os quais a inserção no mundo do trabalho prevalece sobre a frequência à escola. Em 2006, segundo os dados da Pesquisa Nacional de Amostra Domiciliar (PNAD), aproximadamente $52 \%$ dos jovens inseridos na População Economicamente Ativa (PEA) não estudavam, percentual que caiu para 31\% para os jovens de 17 anos. Para fins de estudo, os jovens foram separados entre pobres e não pobres e por em faixas etárias. Merece destaque que os autores tomam a categoria juventude de forma concreta, admitindo a sua imensa heterogeneidade em decorrência de vários indicadores, contemplando, entre eles, a precarização cultural e econômica; por isso, falam em "juventudes". Consideram, contudo, a necessidade de estudar a relação entre escolaridade e trabalho, principalmente entre os mais fragilizados economicamente, uma vez que demandam ações públicas mais imediatas (Ribeiro \& Neder, 2009).

As conclusões relativas às taxas de desocupação são as esperadas: entre os jovens mais pobres, a taxa de desocupação é maior. O que causa surpresa é o que os dados revelam a partir da relação entre anos de escolaridade e desocupação (idem, ibid.). Não obstante as taxas de escolaridade entre os mais pobres terem aumentado como resposta à complexificação do trabalho e da elevação dos requisitos de escolaridade para acesso a emprego, apontando como característica deste segmento na atualidade "a vivência, com maior intensidade, da simultaneidade de várias fases que marcam sua transição para a vida adulta" (idem, ibid., p. 493), ainda prevalece a saída antecipada da escola, como mostram os indicadores apresentados no item anterior.

Ao tratar da relação entre escolaridade e desocupação, a hipótese que prevalece é de que a baixa escolaridade é um dos fatores que dificulta a inserção no mundo do trabalho, a par da diminuição dos postos no mercado de trabalho e da disponibilidade, neste mercado, de trabalhadores desempregados, mais velhos e experientes. Contudo, os resultados obtidos pelo estudo mostram que a taxa de desocupação dos jovens mais pobres, que têm entre 11 a 14 anos de estudos, o que corresponderia ao ensino médio, pelo menos incompleto, não se reduziu; ao contrário, se elevou, mostrando que o esforço educacional deste segmento não diminui suas dificuldades de obtenção de ocupação. Assim, são os jovens pobres, mesmo escolarizados, os que têm mais dificuldade de acesso a trabalho (Ribeiro \& Neder, 2009, p. 505). 
Os autores apontam algumas variáveis que podem contribuir para as maiores taxas de desocupação dos jovens pobres mais escolarizados: "background familiar e qualidade da educação" (idem, ibid.).

Em que pese a necessidade da realização de outros estudos para melhor compreender essas relações, entre eles a comparação da taxa de desocupação dos jovens pobres que concluem o ensino médio nas modalidades educação geral, educação profissional integrada ao ensino médio (regular e PROEJA) e ensino técnico, as conclusões apresentadas pelo estudo permitem fortalecer o poder explicativo da hipótese de que, se a modalidade disponível para os jovens trabalhadores é o ensino médio de educação geral, preferencialmente noturno, de fato passa a ser esta "a escola para os filhos dos outros", revestida antes de caráter certificatório do que da qualidade social necessária para favorecer uma inclusão menos subordinada, como já apontamos em outros estudos (Kuenzer, 2006 e 2007). Ou, como já se indicou, quando se "disponibiliza” a versão média de educação geral para os trabalhadores, isso se faz por meio da oferta precarizada. Para os filhos da burguesia e pequena burguesia, as escolas médias de educação geral ofertadas pela iniciativa privada atendem às suas demandas de acesso ao ensino superior; para os estratos médios e para parcela menos precarizada da classe trabalhadora, os cursos de educação profissional e tecnológica ofertados pelo setor público, embora de reduzida oferta, atendem à necessidade de inserção no mercado de trabalho, com o que viabilizam seu acesso ao ensino superior, na busca por ascensão social.

Desnuda-se, dessa forma, o discurso do Banco Mundial nos anos de 1990, que impactou significativamente a decisão acerca da ruptura entre educação profissional e tecnológica e educação geral, no Brasil e na América Latina (Zibas, 1993; Kuenzer, 1997).

Do ponto de vista do PNE 2011-2020, entendo que esta é a questão crucial a ser enfrentada: a mera ampliação do acesso em propostas que não atendem às necessidades de participação social e produtiva dos que vivem do trabalho não é suficiente, embora tenhamos claro, como já explicitado, que esta ampliação é urgente e necessária, com a qualidade possível. A busca de uma nova qualidade não pode justificar a inércia na expansão da oferta. Há metas, contudo, que precisam ser priorizadas, para cuja efetivação torna-se necessário vultoso financiamento, a ser equacionado por estratégias de colaboração no âmbito da institucionalização do SNE. Entre elas, a mais importante 
é a disponibilização ampliada da oferta de educação profissional integrada ao ensino médio para os que vivem do trabalho, como estratégia de enfrentamento dos efeitos perversos da dualidade invertida. Embora o governo tenha investido significativamente nesta ampliação, as vagas ainda são reduzidas.

Contudo, há ainda outro ponto a considerar: a ampliação da oferta da modalidade integrada não será efetiva se não forem enfrentadas a seletividade que continua caracterizando a oferta na rede pública federal e a organização curricular que vem sendo implementada em todas as esferas. Estas dimensōes, por diversos mecanismos, entre eles a avaliação para ingresso e a elaboração de propostas pedagógicas, que justapõem a formação geral e a específica em longos percursos que transpõem a versão tradicional do ensino técnico, têm gerado índices elevados de evasão e repetência, que se acentuam na versão PROEJA, onde a evasão tem estado próxima de $50 \%$. Há que construir uma proposta de ensino médio integrado que supere a mera justaposição dos componentes geral e específico dos currículos, sem cair no engodo de projetos com reduzida sistematização do conhecimento e a negar a necessidade de formação teórica para os trabalhadores, mediante uma rigorosa articulação entre teoria e prática, a partir da prática social e dos processos de trabalho. Ou seja, há que investir, através do PNE, em um rigoroso trabalho de organização curricular para esta modalidade, o que se associa à meta de qualificar os docentes, mediante formação inicial e continuada, necessidade evidenciada por muitos deles, inclusive com formação em nível de mestrado e doutorado, que têm reportado essa dificuldade em distintos espaços de discussão e de pesquisa.

Parte desta dificuldade vem do fato de que a formação em nível de mestrado e doutorado não contempla, para além do estágio de docência, efetiva formação para o ensino em qualquer nível, etapa ou modalidade, mas principalmente em educação profissional e tecnológica, centrandose em conhecimentos específicos das áreas de estudo. Portanto, a inclusão de formação para a docência em educação profissional e tecnológica é uma meta também a ser considerada pelo PND, no âmbito da pós-graduação stricto senso, pela oferta de formação pedagógica nos cursos específicos, ou como área de concentração e linha de pesquisa nos cursos das áreas de educação, ensino de ciências e interdisciplinar.

Por outro lado, a formação de professores para a modalidade integrada mediante licenciatura não está devidamente equacionada, 
prevalecendo ainda a organização tradicional por disciplina na perspectiva acadêmica. Portanto, outra meta importante, capaz de impactar positivamente a qualidade do ensino médio integrado, é a construção de uma proposta de licenciatura para a educação profissional e tecnológica que tome como eixo a pedagogia do trabalho. Ressalte-se, oportunamente, a necessidade de revisão das diretrizes curriculares para a formação de professores, que não atendem a este tipo de formação.

Tratando-se de organização curricular, embora com outro foco, os problemas são os mesmos para o ensino médio de educação geral e, neste aspecto, também impactam negativamente em muitos casos, como na formação oferecida à burguesia pelas instituições privadas: propostas pedagógicas academicistas, caracterizadas ainda por uma concepção de aprendizagem tipicamente taylorista/fordista, fracamente vinculada à prática social e à realidade do jovem na atualidade e centrada em disciplinas fragmentadas, tratadas formalmente, que articulam precariamente teoria e prática e que, de modo geral, não promovem o que é a finalidade do ensino médio: o desenvolvimento da autonomia intelectual, ética e estética. Nesse sentido, valem as observações relativas à necessidade de uma nova organização curricular, acompanhada de programas de formação inicial e continuada de professores, mais adequada à nova realidade do jovem que vive em relaçôes sociais e produtivas marcadas pela exclusão, pela ausência de projeto de futuro, pela complexidade tecnológica e dos meios de comunicação, pela flexibilidade, pela instabilidade, pela intensificação e pelo estresse, para citar apenas as dimensóes mais evidentes.

Há, pois, que investir na construção coletiva de uma nova proposta pedagógica que, contemplando a diversidade, articule formação científica e sócio-histórica à formação tecnológica, promovendo autonomia intelectual e ética, mediante o domínio teórico-metodológico do conhecimento socialmente produzido e acumulado, de modo a preparar os jovens para atender e superar as revoluções na base técnica de produção, com seus perversos impactos sobre a vida individual e coletiva. Mediante uma modalidade politécnica ou mesmo profissional, esta proposta deverá integrar, necessariamente, ciência, tecnologia, trabalho e cultura. Isso significa dizer que a unitariedade da escola média será assegurada pela garantia do acesso, da permanência e do sucesso em escolas de qualidade, independentemente da origem de classe de seus alunos; a modalidade, se integrada ou de educação geral, desde que assegurada a qualidade, deve contemplar os interesses e necessidades dos seus alunos. 
Há, contudo, que ressalvar a necessidade tanto de ampliar a oferta da modalidade integrada, quanto de investir maciçamente na qualidade da modalidade de educação geral, com a finalidade de reverter os efeitos perversos da dualidade invertida.

Para tanto, a discussão acerca da necessidade do estabelecimento de padrôes mínimos de qualidade precisa avançar, de modo a subsidiar a formulação de metas relativas à infraestrutura física e pedagógica; temas antigos precisam ser retomados, tais como construçóes escolares apropriadas ao ensino médio, considerando as características das "juventudes" que as frequentam; equipamentos, laboratórios, bibliotecas e outros espaços culturais e desportivos precisam ser disponibilizados, pois não há como ter qualidade em espaços precários. Por outro lado, há novas dimensões a contemplar, com destaque para as políticas de assistência ao estudante e para a constituição de espaços e projetos pedagógicos que atendam à diversidade cultural, étnica e de gênero, que assegurem acessibilidade, que sejam inclusivas e que ofereçam segurança.

Embora estas dimensões estivessem contempladas no PNE 20012010, não há dados que permitam avaliar os investimentos nesta área, em que pese a expressiva expansão dos Institutos Federais de Educação, ainda insuficiente para atender à demanda.

Ao finalizar este item, não é demais relembrar que a elaboração desta nova síntese não é um problema pedagógico, mas um problema político, uma vez que a dualidade estrutural, como já se afirmou anteriormente, tem suas raízes na forma de organização da sociedade, expressando as relaçôes entre capital e trabalho; em que pese os avanços que possam ocorrer com a ampliação da oferta e com a melhoria da qualidade, mediante políticas públicas, é preciso compreender que não é possível superar a dualidade estrutural a partir da escola, senão a partir de transformações na sociedade.

É neste contexto que o PNE, como fruto da negociação de interesses contraditórios, pode contribuir efetivamente para avanços na construção de uma sociedade menos desigual, desde que não se constitua em mera formalidade. Esta afirmação é necessária porque todos os temas aqui elencados foram contemplados no PNE anterior e constam do Documento Final da CONAE e dos subsídios apresentados pelo CNE, tendo em vista a proposição do PNE para o novo decênio. 


\section{Considerações finais}

A análise levada a efeito neste texto possibilita concluir que o grande desafio do PNE 2011-2020 é conferir materialidade ao discurso da educação básica como direito de todos e responsabilidade do Estado, mediante a institucionalização do Sistema Nacional de Educação como instância integradora dos esforços pela democratização da oferta de ensino médio com qualidade. Para tanto, o PNE deverá definir claramente a diretriz indicativa para os investimentos e para as açóes, reposicionando, mediante a prática colaborativa entre os poderes públicos, a ação pública estatal, uma vez que há evidências empíricas que comprovam que a pulverização de recursos ou seu repasse para instituições privadas responderem pelas obrigaçôes do Estado, mediante programas pretensamente afirmativos, não tem apresentado efetividade social, no sentido de impactar positivamente os indicadores de escolaridade, emprego e renda.

Para que o PNE possa de fato cumprir suas finalidades, considerase absolutamente necessária, em se tratando de ensino médio, a realização de estudos e diagnósticos consistentes, para o que é fundamental o estabelecimento de uma base de dados devidamente tratados para permitir o acompanhamento dos indicadores de acesso, permanência e sucesso em séries históricas, articulados a dados de emprego e renda.

Do ponto de vista da qualidade, há necessidade de uma avaliação crítica dos indicadores atuais produzidos pelas metodologias usadas no ENEM e na definição do IDEB, com a finalidade de verificar se, de fato, apreendem a complexidade de realidades tão diversas, ou se, desconsiderando as diferenças, subsidiam a formulação de políticas e programas que acentuam ainda mais as desigualdades.

Estas providências se tornam indispensáveis ao se pretender estabelecer metas físico-financeiras com indicadores bem definidos que orientem a negociação de um pacto federativo, que realmente impacte o acesso com qualidade social no ensino médio, em contraposição à década perdida. Só assim será possível à sociedade civil e ao próprio governo proceder a um acompanhamento criterioso dos resultados das políticas e dos programas públicos, visando à qualificação do ensino médio para os que vivem do trabalho.

Recebido e aprovado em agosto de 2010. 


\section{Notas}

1. A avaliação do Plano Nacional de Educação levada a efeito por equipe da Universidade Federal de Goiás (UfGO) e outras universidades, com apoio do INEP e da SEB/MEC, evidencia claramente estes limites.

2. Dados da Sinopse Estatística da Educação Básica (InEP/MEC, 2009).

3. Dados da Avaliação do Plano Nacional de Educação 2001-2008.

4. Dados da Avaliação do Plano Nacional de Educação 2001-2008.

5. Dados do IBGE/PNAD, sistematizados pelo INEP/DTDIE.

6. Dados da Avaliação do Plano Nacional de Educação 2001-2008.

7. Idem.

8. Idem.

9. Disponível em: <sistemaideb.inep.gov.br>. Consulta em: 1ำ ago. 2010.

\section{Referências}

KUENZER, A.Z. Ensino médio e profissional: as políticas do Estado neoliberal. São Paulo: Cortez, 1997. 104p.

KUENZER, A.Z. A educação profissional nos anos 2000: a dimensão subordinada das políticas de inclusão. Educação \& Sociedade, Campinas, v. 27, n. 96, p. 877-910, out. 2006.

KUENZER, A.Z. Da dualidade assumida à dualidade negada: o discurso da flexibilização justifica a inclusão excludente. Educação \& Sociedade, Campinas, v. 28, n. 100, p. 1153-1178, out. 2007.

RIBEIRO, R.; NEDER, H. Juventude(s): desocupação, pobreza e escolaridade. Nova Economia, Belo Horizonte, v. 19, n. 31, p. 475506, set./dez. 2009.

ZIBAS, D.M.L. A função social do ensino médio na América Latina: é sempre possível o consenso? Cadernos de Pesquisa, São Paulo, n. 85, p. 26-32, maio 1993.

ZIBAS, D.M.L. A reforma do ensino médio no Chile: vitrine para a América Latina? Cadernos de Pesquisa, São Paulo, n. 115, p. 233-262, mar. 2002. 


\section{Documentos}

BRASIL. Conselho Nacional de Educação (CNE). Indicações para subsidiar a construção do Plano Nacional de Educação: 2011-2020. Brasília, DF, 2009.

BRASIL. Ministério da Educação. Instituto Nacional de Estudos e Pesquisas Educacionais (INEP). Avaliação do Plano Nacional de Educação: 2001-2008. Brasília, DF: MEC/INEP, 2009.

CONFERÊNCIA NACIONAL DE EDUCAÇÃO (CONAE), 2010, Brasília, DF. Construindo o Sistema Nacional Articulado de Educação: o Plano Nacional de Educação, diretrizes e estratégias. Brasília, DF: MEC, 2010 . 